\title{
Damage-Based Seismic Performance Evaluation of Reinforced Concrete Frames
}

\author{
YeongAe Heo'), and Sashi K. Kunnath ${ }^{2), *}$
}

(Received May 1, 2013, Accepted July 9, 2013)

\begin{abstract}
A damage-based approach for the performance-based seismic assessment of reinforced concrete frame structures is proposed. A new methodology for structural damage assessment is developed that utilizes response information at the material level in each section fiber. The concept of the damage evolution is analyzed at the section level and the computed damage is calibrated with observed experimental data. The material level damage parameter is combined at the element, story and structural level through the use of weighting factors. The damage model is used to compare the performance of two typical 12-story frames that have been designed for different seismic requirements. A series of nonlinear time history analyses is carried out to extract demand measures which are then expressed as damage indices using the proposed model. A probabilistic approach is finally used to quantify the expected seismic performance of the building.
\end{abstract}

Keywords: damage model, frame building, seismic performance.

\section{Introduction}

There is general agreement that new procedures are essential for the evaluation of seismic safety of existing structures and for the design of new structures to meet specified performance objectives. There have been several efforts to develop performance based seismic engineering methodologies resulting in guideline documents such as ATC-40 (1996), FEMA-350 (2000) and FEMA-356 (2000). While these documents offer a starting point to the eventual goal of assessing building performance to design level earthquake loads, there is still much work that needs to be done to facilitate reliable seismic performance assessment. All performance-based methodologies share common elements which can roughly be itemized into the following sequence of steps:

- Definition of a performance objective that describes a level of performance which is associated with a specific seismic hazard

- Estimation of seismic demands on the system and its components through detailed structural analysis (preferably nonlinear)

\footnotetext{
${ }^{1)}$ Offshore Tech. R\&D of Marine and Offshore Research Inst., Samsung Heavy Ind., Seoul, Korea.

${ }^{2)}$ Department of Civil and Environmental Engineering, University of California, Davis, CA 95616, USA.

*Corresponding Author; E-mail: skkunnath@ucdavis.edu Copyright ( $\odot$ The Author(s) 2013. This article is published with open access at Springerlink.com
}

- Evaluation of the performance (at the system and component level) to verify that the performance objective has been met.

While efforts to improve specific aspects of the seismic evaluation process have progressed over the past decade, there remains the need for a general framework that incorporates seismic demand and performance assessment into a comprehensive strategy. A general probabilistic framework is proposed in this paper to assess seismic performance of reinforced concrete frame buildings using a new damagebased performance measure that also considers variability in ground motion characteristics.

\section{Material-Based Damage Model}

Current guideline documents such as FEMA-356 (2000) utilize inter-story drift ratio and plastic rotation to establish building performance levels such as immediate occupancy, life-safety, and collapse prevention. While these measures provide information on the deformation of elements and the displaced profiles at critical states, they are inadequate in themselves to provide an assessment of the state of damage or proximity to collapse.

A review of the literature reveals that there are essentially five approaches to damage modeling: estimates based on measures of deformation and/or ductility; models based on the degradation of a selected structural parameter (typically stiffness); models developed from considerations of energydissipation demand and capacity; hybrid formulations combining some aspects of the aforementioned parameters; and more complex theories based on concepts derived from 
fatigue models. Comprehensive reviews of damage modeling techniques can be found in Williams and Sexsmith (1995) and Heo (2009).

Since the response of common structural engineering materials such as steel and RC from the elastic state to failure is represented by yielding, plastic or irreversible behavior, crack growth, and fatigue during monotonic and cyclic loading, it is possible to represent such deterioration phenomena by a numerical model which can be incorporated in fiber-based discretization of a section for material-based damage estimation at the element level.

\subsection{Damage Modeling at Constitutive Level}

In this section, a damage model is introduced at the material level that is related to the response of the section deformation. This deformation is characterized by the stress and strain in the fibers of the cross-section.

\subsubsection{Damage in Concrete Fiber}

Strains at the threshold of damage initiation, attainment of compressive strength, and residual strength of crushed concrete are defined as damage parameters. Damage is considered only in the core concrete because it was determined that calibrating the damage state to compression damage in the core was a better indicator of section damage than incorporating deterioration in both core and cover concrete. Other measures of concrete damage such as tensile cracking was found to be unimportant since damage from tensile loading is better reflected in reinforcing steel. Moreover, the response in compression governs the section damage in the concrete core. The constitutive model proposed by Mander et al. (1988) is used to evaluate the stressstrain response of the confined concrete.

A simple bilinear model is proposed in Eq. (1) and (2) assuming that the damage index is 1.0 when the accumulated plastic strain reaches the strain at the residual strength:

$$
\begin{aligned}
& D_{c i}=\frac{D_{c u}\left(f-f_{c d}\right)}{\left(f_{c u}-f_{c d}\right)} \text { for } \varepsilon \leq \varepsilon_{c u} \\
& D_{c i}=1+\frac{\left(1-D_{c u}\right)\left(f-f_{c f}\right)}{\left(f_{c f}-f_{c u}\right)} \text { for } \varepsilon>\varepsilon_{c u}
\end{aligned}
$$

where $D_{c i}$ is the concrete damage index at the $i$ th concrete fiber, $D_{c u}$ denotes the damage index at the compressive strength of concrete, $f_{c d}$ is the strength at damage initiation, $f_{c u}$ is the concrete compressive strength, $f_{c f}$ is the residual strength, and $\varepsilon_{c u}$ denotes strain at concrete compressive strength. As shown in Fig. 1, the damage rate changes at the peak compressive strength according to $D_{c u}$ which can be determined by the ratio of the degraded strength at the failure $\left(f_{c u}-f_{c f}\right)$ to the compressive strength $\left(f_{c u}\right)$ denoted by $D_{c u}$ as follows:

$$
D_{c u}=\frac{\varepsilon_{c u}-\varepsilon_{c d}}{\varepsilon_{c f}-\varepsilon_{c d}}
$$

\subsubsection{Damage in Reinforcing Steel Fibers}

While the response of reinforcing steel beyond the elastic phase is described through yielding, hardening, softening, and fracture under monotonic loading, these monotonic parameters are inadequate to incorporate random cyclic effects such as strength degradation because steel is vulnerable to fatigue damage under seismic loads. It is more efficient to consider damage due to cyclic fatigue since it encompasses the combined effect of multiple damage parameters. Buckling of reinforcing bars is an important phenomenon that occurs under both monotonic and cyclic loading however, a cyclic fatigue model can also include buckling effects. Therefore Miner's (1945) linear damage rule shown in Eq. (4) is applied to compute damage in reinforcing steel fiber:

$$
D_{s i}=\frac{1}{\sum_{j=1}^{n}\left(2 N_{f}\right)_{j}}
$$

$D_{s i}$ denotes the damage index in the $i$ th steel fiber, and $\left(2 N_{f}\right)_{j}$ denotes the number of half-cycles to failure at the plastic strain amplitude corresponding cycle $j$ which is described in Coffin $(1954,1971)$ and Manson (1953). $D_{s i}$ is initialized to zero until the cumulative plastic strain attains the damage initiation threshold and it reaches unity (ideally) when the rebar is fractured. It is implicitly assumed that the fatigue model is calibrated in a manner that incorporates buckling. This means that the strain is measured across a significant characteristic length that includes buckling. In experiments carried out by Brown and Kunnath (2004), the fatigue life of reinforcing bars is computed using an effective length that includes the buckling zone. Additional details to

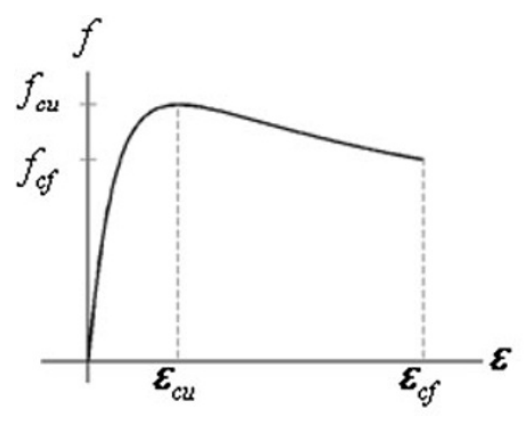

(a) Stress-strain response

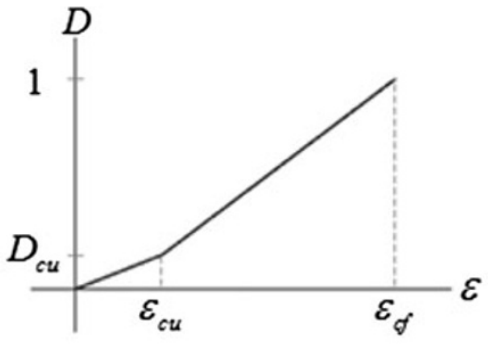

(b) Damage evolution

Fig. 1 Stress-strain response of confined concrete and corresponding damage evolution. 
estimate $\left(2 N_{f}\right)_{j}$ can be also found in Kunnath and Chai (2004).

\subsubsection{Structural Damage at Element Level}

It is necessary to first generate damage at the element level from the section damage at the fiber level discussed in the previous section. It is reasonable to consider the damage index of the most critical fibers for concrete and reinforcing steel as representative damage indices for each section as defined below:

$$
\begin{aligned}
& D_{c x}^{B}=\max \left(D_{c i}^{B}\right), D_{s x}^{B}=\max \left(D_{s i}^{B}\right) \\
& D_{c x}^{C}=\max \left(D_{c i}^{C}\right), D_{s x}^{C}=\max \left(D_{s i}^{C}\right)
\end{aligned}
$$

In the above equations, $D_{c x}$ and $D_{s x}$ denotes concrete and reinforcing steel damage index respectively on the $x$ th element for each story and superscripts $B$ and $C$ denote beam and column elements. For a $n$ story frame structure with $m$ bays, $x=1,2 \ldots . m$ for beams and $x=1,2 \ldots m+1$ for columns for each story. It is assumed that the failure of any critical concrete or reinforcing steel fiber leads to section failure in the member. This assumption may be conservative if the concrete crushing strain is achieved prior to the fatigue failure of the reinforcing bar, however, the ultimate compressive strain in confined concrete is a severe damage state that also impacts the damage in the steel. Since the failure of a local member detected by the proposed damage model at the material level progressively affects adjacent members, it can lead to eventual collapse of the entire system. Hence the damage index at the material level can govern the damage index at the element as well as the system level.

The combination of individual section damage to compute the element damage requires the implementation of weighting factors. In the study, based on studying different weighting factors, it was determined that the damage index itself is quite effective to be regarded as the weighing factor in estimating section damage. This approach has also been used previously by Bracci et al. (1989). In Eq. (7) and (8), $w_{c x}$ and $w_{s x}$ denotes the weighting factor for the damage index of the extreme concrete and steel fiber for the $x$ th element on each story respectively.

$$
\begin{aligned}
& w_{c x}^{B}=\frac{D_{c x}^{B}}{\left(D_{s x}^{B}+D_{c x}^{B}\right)}, w_{s x}^{B}=\frac{D_{s x}^{B}}{\left(D_{s x}^{B}+D_{c x}^{B}\right)} \\
& w_{c x}^{C}=\frac{D_{c x}^{C}}{\left(D_{s x}^{C}+D_{c x}^{C}\right)}, w_{s x}^{C}=\frac{D_{s x}^{C}}{\left(D_{s x}^{C}+D_{c x}^{C}\right)}
\end{aligned}
$$

Finally, the damage index of $x$ th beam and column element $\left(D_{x}^{B}, D_{x}^{C}\right)$ is estimated as follows:

$$
D_{x}^{B}=D_{s x}^{B} w_{s x}^{B}+D_{c x}^{B} w_{c x}^{B}, D_{x}^{C}=D_{s x}^{C} w_{s x}^{C}+D_{c x}^{C} w_{c x}^{C}
$$

\subsubsection{Structural Damage at Story Level}

Damage is computed at each story level to facilitate the assessment of structural performance under earthquake loads. The same concept of using the damage index as weighting factor can be applied in computing the damage for each story as shown below:

$$
D_{y}^{B}=\frac{\sum_{x=1}^{m}\left(D_{x}^{B}\right)^{2}}{\sum_{x=1}^{m} D_{x}^{B}}, D_{y}^{C}=\frac{\sum_{x=1}^{m}\left(D_{x}^{C}\right)^{2}}{\sum_{x=1}^{m} D_{x}^{C}}
$$

$D_{y}^{B}$ and $D_{y}^{C}$ denote the damage indices for the $y$ th story of a $n$-story frame structure. Since columns are more critical structural elements than beams, it is necessary to introduce the concept of an importance factor. In this study, this is achieved by imposing a higher weighting factor for the failure of column elements compared to beams. Assuming that a story fails when the combine damage index of the columns in that story reaches 0.5 , the story damage index for columns $\left(D_{y}^{C}\right)$ needs to be updated as given in Eq. (11):

$$
D_{y}^{C}=\left\{\begin{array}{l}
1\left(D_{y}^{C} \geq 0.5\right) \\
\text { adjusted by interpolation }\left(D_{y}^{C}<0.5\right)
\end{array}\right.
$$

Finally, the damage index of the $y$ th story using the weighted beam and column damage index of each story is computed as given below:

$$
D_{y}=\frac{\left(D_{y}^{B}\right)^{2}+\left(D_{y}^{C}\right)^{2}}{D_{y}^{B}+D_{y}^{C}}
$$

\section{Model Validation}

In this section, the applicability of the proposed model to assess the damage to components subjected to cyclic loading is examined. Figure 2 displays the cyclic force-deformation response of the ductile column tested by Mo and Wang (2000). The resulting stress-strain histories in the critical confined concrete fiber and critical reinforcing steel fiber is shown in Figs. 3 and 4, respectively. Figures 3 and 4 also show the computed damage histories. In this case, the proposed damage model suggests that failure of the section is initiated by cyclic fatigue of the critical reinforcing bar.

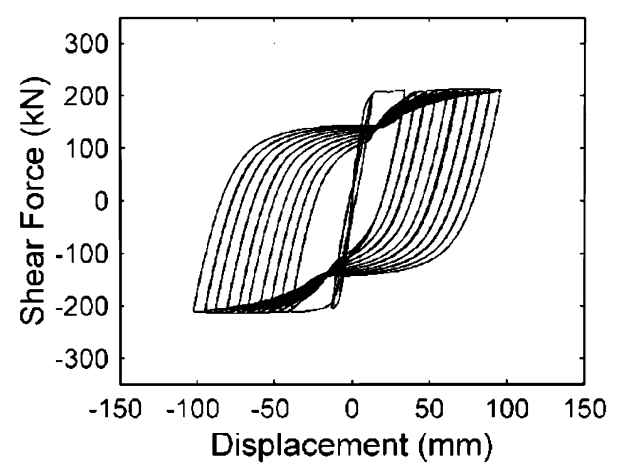

Fig. 2 Force-displacement response of ductile column under cyclic lateral loading (Test by Mo and Wang 2000). 


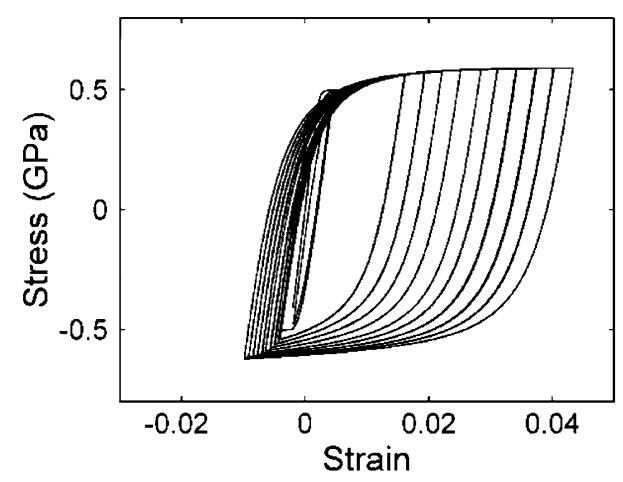

(a) Stress-strain response

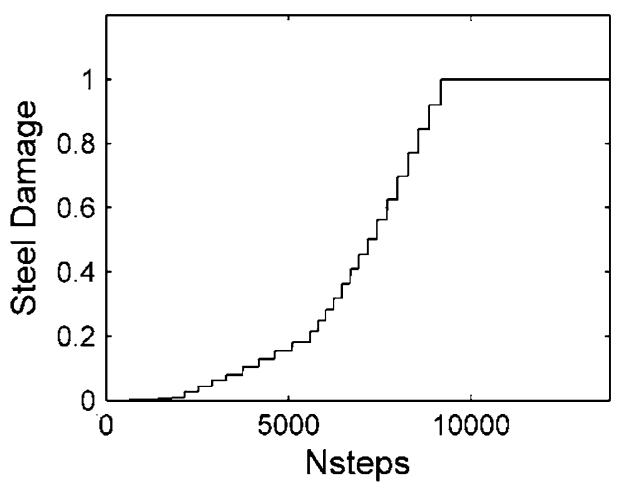

(b) Damage progression

Fig. 3 Stress-strain response of critical reinforcing steel fiber and corresponding damage progression.

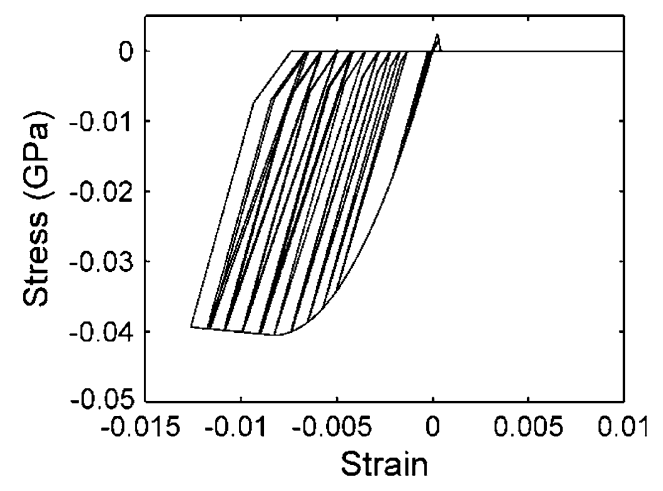

(a) Stress-strain response

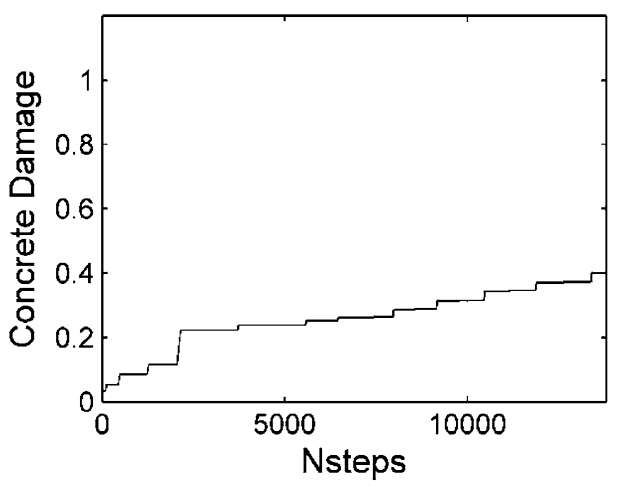

(b) Damage progression

Fig. 4 Stress-strain response of critical confined concrete fiber and corresponding damage progression.

\section{Probabilistic Performance Assessment}

The proposed assessment requires the development of a statistically reliable prediction model of the selected seismic demand parameter. The prediction model is essentially a regression model based on the analysis of large data sets that consist of ground motion parameters from recorded motions and simulated data from nonlinear structural simulations. In the present study, the following ground motion intensity measures are considered in the development of the response model: spectral acceleration at the fundamental period, $S a_{T 1}$, the spectral acceleration at the second mode period, $S a_{T 2}$, and the spectral acceleration at the third mode period $\mathrm{Sa}_{T 3}$, the spectral acceleration corresponding to 1.5 times the fundamental period $S a_{T 4}$, and the spectral acceleration at 2.0 times the fundamental period $S a_{T 5}$.

Expressing the demand as a linear combination of one or more intensity measures and examining the resulting residuals is a simple way to assess the effectiveness of a predictive demand model. In this study, the following regression models, where the structural damage index $(D I)$ is selected as the primary response parameter, were considered:

$$
\begin{aligned}
E(\ln D I)= & c_{0}+c_{1} \ln \left(S a_{T 1}\right)+c_{2} \ln \left(S a_{T 3}\right)+c_{3} \ln \left(S a_{T 4}\right) \\
& +c_{4} \ln \left(S a_{T 5}\right)
\end{aligned}
$$

$$
\begin{aligned}
& E(\ln D I)=c_{0}+c_{1} \ln \left(S a_{T 1}\right)+c_{2} \ln \left(S a_{T 3}\right) \\
& E(\ln D I)=c_{0}+c_{1} \ln \left(S a_{T 1}\right)
\end{aligned}
$$

Note that $D I$ refers to the peak story damage index. Equation (13) is referred to as Model A, Eq. (14) is Model C and Eq. (15) is Model $\mathrm{E}$ in the ensuing discussions. Each response prediction equation can be evaluated statistically against the original data to generate the mean and standard deviation of the model predictions. Finally, the probability that a set of ground motions causes a selected damage index to be exceeded for a given earthquake scenario is computed by integrating the probability distribution of the structural response measure $(D I)$ over the truncated area from $\varepsilon_{\delta \ln (D I)}^{\prime}$ (the value of the normalized residual corresponding to a specified damage state, (di) to infinity:

$$
\begin{aligned}
& P\left(D I g t ; d i \mid S a_{T i}\right)=\int_{\varepsilon_{\delta \ln D I}^{\prime}}^{\infty} f_{\varepsilon \ln D I} d \varepsilon_{\delta \ln D I} \\
& f_{\varepsilon \delta \ln D I}=N\left(\mu_{\delta \ln D I}, \sigma_{\delta \ln D I}\right) \\
& D I=\exp (\ln D \hat{I}) \exp \left(\varepsilon_{\delta \ln D I} \sigma_{\delta \ln D I}\right)
\end{aligned}
$$

In the above equations, $f_{\varepsilon} \delta \ln D I$ is the normal distribution function of the normalized residuals of the damage indices with mean $\mu_{\delta \ln D I}$ and standard deviation $\sigma_{\delta \ln D I}$. The 


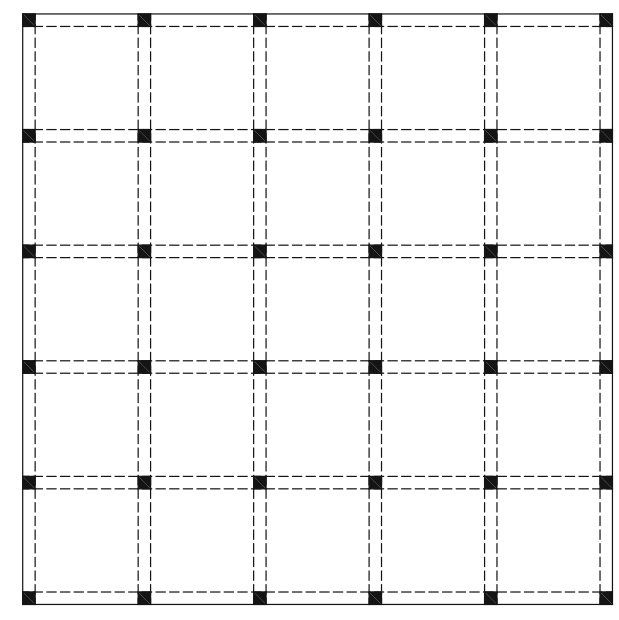

(a) Plan

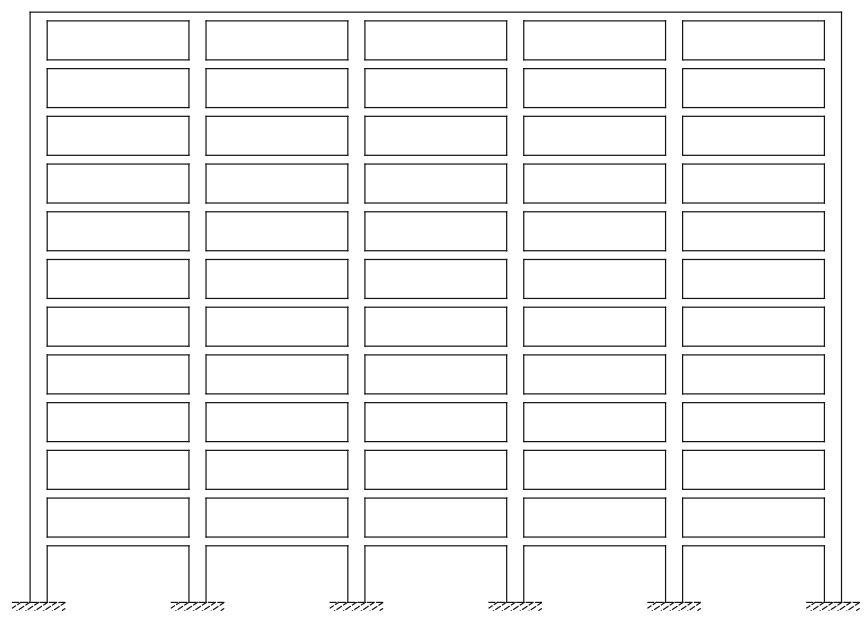

(b) Elevation

Fig. 5 Plan and typical frame elevation of 12-story buildings considered in evaluation.

cumulative probability density distribution represented by Eq. (16) is referred to as a fragility function.

\section{Case Study}

The proposed methodology is applied to the assessment of two typical 12-story RC frame buildings: a modern RC building designed to current seismic provisions (referred to as Building A) and an older RC building (referred to as Building B) designed to pre-1971 standards. Consistent with the theme of the present study, these two buildings represent two important structural types: ductile and nonductile systems. The lowest level of both building is 15 feet high while the remaining floors are 12 feet. The plan dimensions of the building are $120 \times 120$ feet with 5 equal bays of 24 feet in each direction. The choice of a symmetric floor plan allows a single typical frame in either direction to be analyzed as a two-dimensional frame. A plan view and typical frame elevation of the building is shown in Fig. 5.

Building $\mathrm{A}$ is assumed to be a standard office building located in San Francisco (37.46 N, 122.25 W). This building is designed to meet the provisions of Seismic Design Category D as specified in ASCE 7-05. The following parameters were used in the design:

$$
\begin{aligned}
& S_{S}=1.50 \mathrm{~g} ; \quad S_{1}=0.67 \mathrm{~g} ; \quad I=1.10 ; \quad C_{d}=5.5 ; \\
& R=8.0
\end{aligned}
$$

Using the above values, the design base shear is $2325 \mathrm{kips}$ and the approximate code-based fundamental period is $1.43 \mathrm{~s}$ while the true first mode period based on input material and element properties was determined to be $2.1 \mathrm{~s}$. The final design is based on using normal weight concrete (150 pcf) with a compressive strength $f_{c}^{\prime}=4,000$ psi and reinforcing steel with a nominal yield strength $f_{y}=60 \mathrm{ksi}$. Section sizes and details of the required flexural and shear reinforcement is presented in Table 1 . To simplify the design process, equal top and bottom reinforcement is provided in the beam end-sections for both frames corresponding to the largest moment demand from combined lateral and gravity loads.

For Building $\mathrm{B}$, in accordance with the provisions of SEAOC 1960, the horizontal force factor $K$ was set to 0.67 , the period-dependent factor $C=0.047$ (based on an approximate period of $1.2 \mathrm{~s}$ ) and the resulting base shear was computed as $733 \mathrm{kips}$. This lateral shear is only $32 \%$ of the required base shear in current practice. The reduction in building weight due to the fact that the building components are smaller is compensated by lower stiffness resulting in a first mode period of $2.45 \mathrm{~s}$ that is comparable to the building designed to the current code. Final section sizes and reinforcement details of the building are displayed in Table 1.

\subsection{Ground Motions Used in Evaluation}

Upon examining the thousands of ground motion records in the Pacific Earthquake Engineering Research (PEER) next generation attenuation (NGA) database (PEER 2005), it was found that a significant majority of the records were low intensity motions that did not induce sufficient inelastic behavior in the structural system being evaluated in this study. Since one of the objectives of the study is to examine the effectiveness of demand and performance measures in the moderate to severe range of structural damage, it was decided to select only 200 ground motions whose PGA exceeds $0.2 \mathrm{~g}$. Of these, exactly half were near fault records (fault distance less than $20 \mathrm{~km}$ ) and the remaining were farfault records. Figs. 6 and 7 show the $5 \%$ damped response spectra for all selected records from the database. Also shown is the mean spectrum of the 100 near fault and far fault records superimposed on the ASCE 7-05 design spectrum for the site.

Simulation models of both 12-story frames were developed in OpenSEES (2011). Among the widely used element models in the context of fiber-based discretization of sections are nonlinear beam-column elements with distributed plasticity. A fully nonlinear beam-column element estimates element deformations by numerical integration of the section 
Table 1 Component sizes and reinforcement details for Buildings A and B.

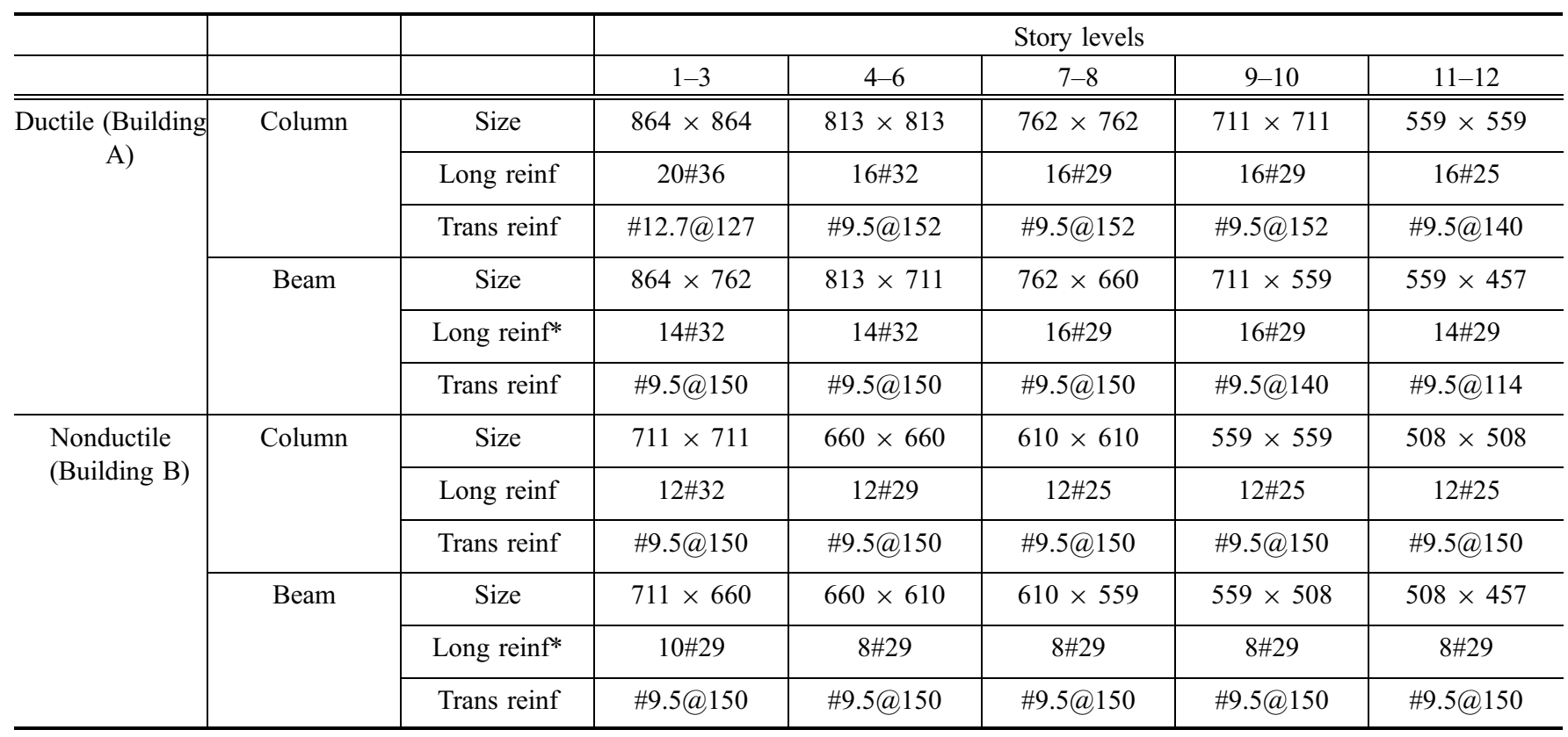

Notation $n$ bars with diameter \#; diameter \# @ spacing; all dimensions in mm.

* Total reinforcement (equal top and bottom reinforcement).

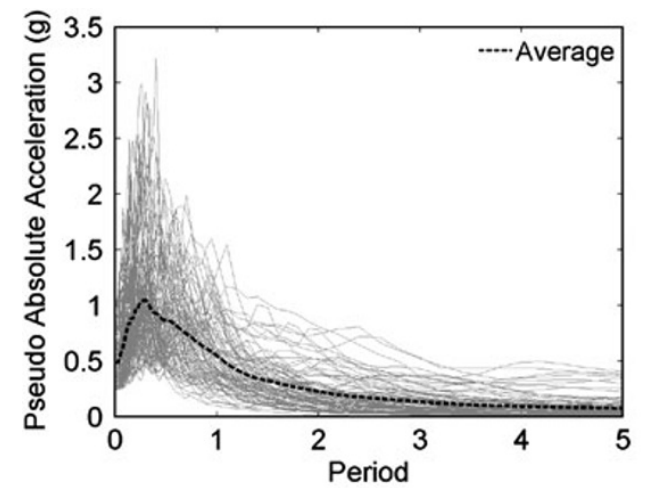

(a)

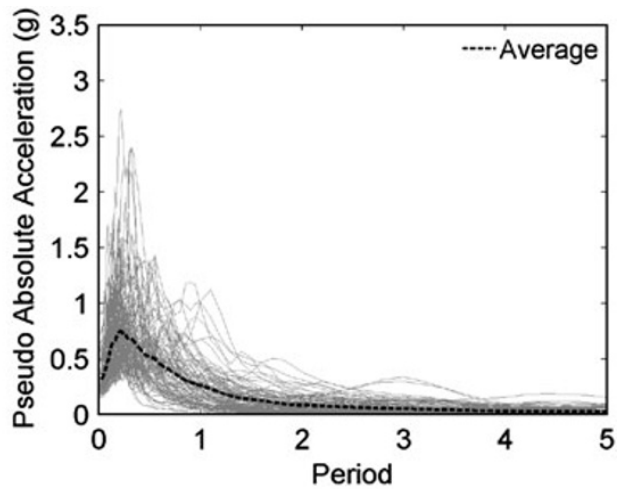

(b)

Fig. 65 \% Damped Response Spectra of selected 200 ground motions: a 100 Near-fault records. b 100 Far-fault records.

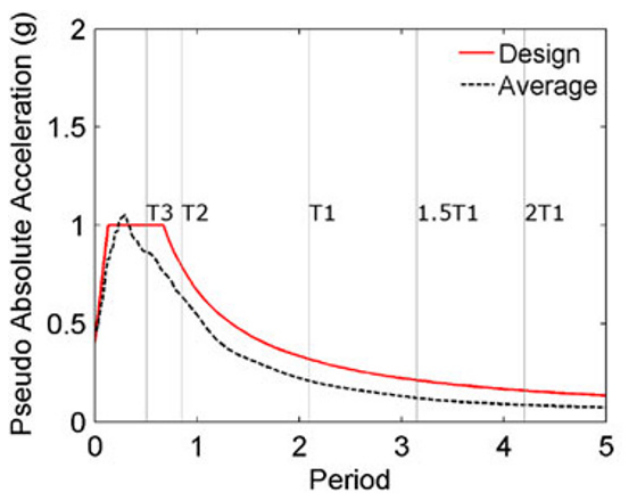

(a)

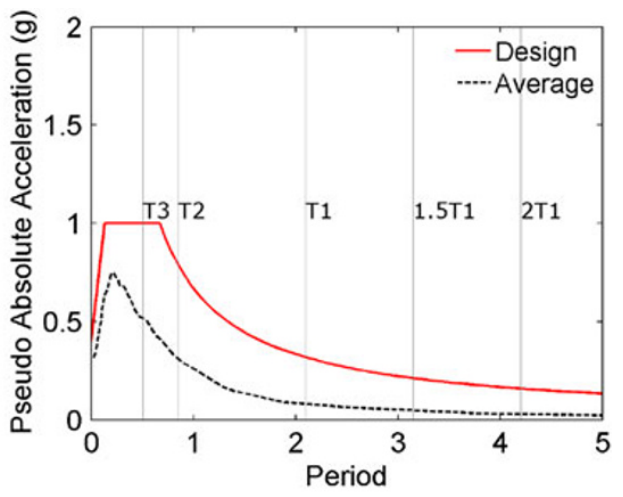

(b)

Fig. 7 Mean spectra and ASCE 7-05 design spectra: a Near-fault motions. b Far-field motions.

deformations. On the other hand, the beam-with-hinges element implemented in OpenSees uses four integration points to compute element deformations assuming fixed plastic hinge lengths at the ends of the element. A complete description of the element formulation is reported by Scott and Fenves (2006). All frame elements were modeled in OpenSees using the Beam-with-Hinges element: a hinge length corresponding to $55 \%$ of the section depth was used 
Table 2 Regression coefficients for demand models given by Eqs. (13)-(15) for Building A.

\begin{tabular}{c|c|c|c}
\hline & Model A & Model C & Model E \\
\hline \hline$\sigma_{\delta D I}$ & 0.1602 & 0.1609 & 0.2221 \\
\hline$\mu_{D I}$ & 0.3982 & 0.3979 & 0.3885 \\
\hline$c_{0}$ & -0.4957 & -0.4980 & -0.3669 \\
\hline$c_{1}$ & 0.3097 & 0.3464 & 0.5059 \\
\hline$c_{2}$ & 0.1172 & 0.1147 & \\
\hline$c_{3}$ & 0.2605 & 0.2577 & \\
\hline$c_{4}$ & 0.0615 & & \\
\hline
\end{tabular}

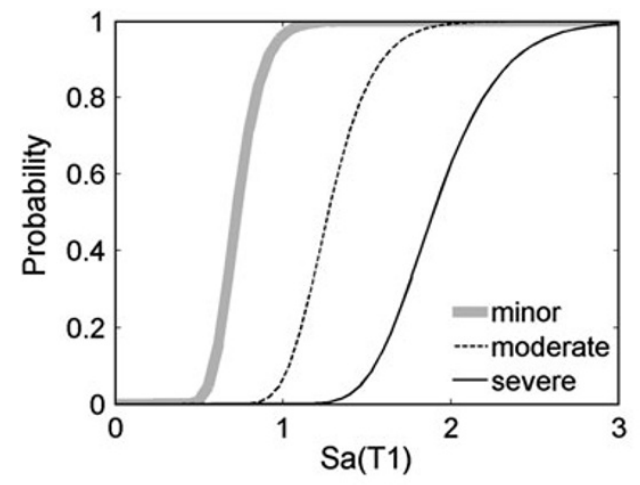

(a)

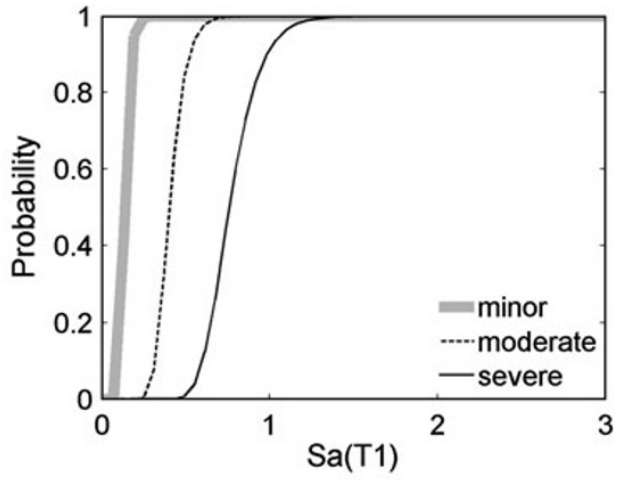

(b)

Fig. 8 Fragility curves for various damage states a Building A, b Building B.

since this value produced deformations and damage measures that correlated well with experimental observations.

In all, 200 nonlinear analyses were carried out with the selected ground motions. The damage model presented in this paper was applied to the computed response quantities. Response models of the form given in Eqs. (13)-(15) were generated and the regression coefficients obtained are listed in Table 2. Only the sample case for Building $\mathrm{A}$ is shown in Table 2.

The damage model was calibrated (see Heo 2009 for additional details) as follows: $D I<0.4$ is classified as Minor Damage; $0.4 \leq D I \leq 0.7$ is considered to result in Moderate Damage while $D I>0.7$ is expected to lead to Severe Damage. The distribution of damage estimates is then used to generate fragility curves as formulated in Eq. (16). Figure 8 shows the probability that each of the building considered in the evaluation study will attain different damage states as a function of the first mode spectral acceleration $S a_{T 1}$.

\section{Concluding Remarks}

The proposed damage model is a preliminary effort to investigate the applicability of material based damage models in seismic performance assessment. The materialbased damage model is found to reproduce observed component damage in a consistent manner so that calibration of the model is possible for different types of section details (ductile and non-ductile). Since fiber-based element models are going to be used more widely in nonlinear analysis of reinforced concrete structures, the development of a robust material-based damage model will greatly facilitate more accurate performance-based assessment. The damage model has been shown in Heo (2009) to compare favorably to wellknown structural response measures such as inter-story drift and member plastic rotation. In this study, the model was used to compare the relative seismic performance of two different buildings designed to different seismic requirements.

\section{Open Access}

This article is distributed under the terms of the Creative Commons Attribution License which permits any use, distribution, and reproduction in any medium, provided the original author(s) and the source are credited.

\section{References}

ATC-40. (1996). Seismic evaluation and retrofit of concrete buildings (Vol. 1). Redwood City, CA: Applied Technology Council. 
Bracci, J., Reinhorn, A. M., Mander, J. B. \& Kunnath, S. K. Deterministic damage model for seismic damage evaluation of RC structures. NCEER report 89-0033. (1989). Buffalo, NY: State University of New York.

Brown, J., \& Kunnath, S. K. (2004). Low-cycle fatigue behavior of reinforcing steel bars. ACI Materials Journal, 101(6), 457-466.

Coffin, L. F. Jr. (1954). A study of the effect of cyclic thermal stresses on a ductile metal. American Society of Mechanical Engineers, 76, 931-950.

Coffin, L. F. Jr. (1971). A note on low cycle fatigue laws. Journal of Materials, 6, 388-402.

FEMA-350. (2000). Recommended seismic design criteria for new steel moment-frame buildings. Washington D.C.: Federal Emergency Management Agency.

FEMA-356. (2000). Prestandard and commentary for the seismic rehabilitation of buildings. Washington D.C: Federal Emergency Management Agency.

Heo, Y. A. (2009). Framework for damage-based probabilistic seismic performance evaluation of reinforced concrete frames. Ph.D. Dissertation, University of California, Davis, $C A$.

Kunnath, S. K., \& Chai, Y. H. (2004). Cumulative damagebased inelastic cyclic demand spectrum. Earthquake Engineering and Structural Dynamics, 33(4), 499-520.
Mander, J. B., Priestley, M. J. N., \& Park, R. (1988). Theoretical stress strain model for confined concrete. Journal of Structural Engineering, 114(8), 1804-1826.

Manson, S. S. (1953). Behavior of materials under conditions of thermal stress. In Heat Transfer Symposium (pp. 9-75) Ann Arbor, MI: University of Michigan Engineering Research Institute.

Miner, M. A. (1945). Cumulative damage in fatigue. Journal of Applied Mechanics, 12, A159-A164.

Mo, Y. L., \& Wang, S. J. (2000). Seismic behavior of RC columns with various tie configurations. Journal of Structural Engineering, 126(10), 1122-1130.

OpenSees. (2011). "Open system for earthquake engineering simulation”. Open source software http://opensees.berkeley. edu. Retrieved 1 June 2009.

PEER. (2005). Strong motion database http://peer.berkeley.edu. Retrieved 4 April 2009.

Scott, M. H., \& Fenves, G. L. (2006). Plastic hinge integration methods for force-based beam-column elements. Journal of Structural Engineering, 132(2), 245-252.

Williams, M. S., \& Sexsmith, R. G. (1995). Seismic damage indices for concrete structures: A state-of-the-art review. Earthquake Spectra, 11(2), 319-349. 